\title{
PRODUÇÃO, TRADIÇÃO E IMPORTAÇÃO: UMA CHAVE PARA A DESCRIÇÃO DA LITERATURA E DA LITERATURA EM TRADUÇÃO' ${ }^{1}$
}

\author{
José Lambert* \\ Katholieke Universiteit Leuven
}

Tradução de Jean-François Brunelière ${ }^{* *}$ e Andréia Guerini ${ }^{* * *}$

\begin{abstract}
Resumo: A questão da cultura tornou-se central nas pesquisas recentes a respeito da tradução. No presente momento, a relação entre tradução e cultura é geralmente aceita pelas teorias canonizadas e a dificuldade consiste em definir o contexto cultural. A cultura é um conceito complexo e múltiplo: qual cultura, que tipo de cultura exatamente? Nas pesquisas empíricas e descritivas, é fundamental estabelecer a natureza exata do contexto cultural e quais são as suas relações com as culturas que o cercam. A tradução representa uma área-chave em qualquer sistema cultural e, ao tentar interpretar a posição de certas traduções em um determinado sis-
\end{abstract}

\footnotetext{
*Possui doutorado em Filologia Românica pela Katholieke Universiteit Leuven. É presidente de honra do CETRA e editor fundador da revista Target (junto com Gideon Toury). Atualmente é professor visitante do Programa de Pós-graduação em Estudos da Tradução na Universidade Federal de Santa Catarina (UFSC). Florianópolis, Santa Catarina, Brasil. E-mail:jose.lambert@arts.kuleuven.be

** Jean-François Brunelière é doutorando do Programa de Pós-graduação em Estudos da Tradução na Universidade Federal de Santa Catarina (UFSC). Florianópolis, Santa Catarina, Brasil. E-mail: jfbruneliere.traducao@gmail.com

*** Possui doutorado em Literatura pela Universidade Federal de Santa Catarina. Pós-doutorado pela Università degli Studi di Padova (2010). É professora do Departamento de Línguas e Literaturas Estrangeiras e Coordenadora da PósGraduação em Estudos da Tradução na Universidade Federal de Santa Catarina. Florianópolis, Santa Catarina, Brasil. E-mail andreia.guerini@gmail.com
} 
tema cultural, não há como fugir de certas lógicas hipotéticas. Toda área cultural parece funcionar como uma combinação sincrônica e diacrônica de, no mínimo, três unidades-chaves: (1) Produção: em termos sincrônicos, tudo o que um sistema cultural produz (documentos, atividades, contatos internos e externos); essa produção ocorre em uma perspectiva diacrônica; (2) Tradição: todas as atividades e posições no eixo diacrônico; dependem (obviamente) das opções que dominam e das seleções (normas); Importação: a seleção organizada de produções de culturas próximas durante a qual a tradução acontece. O perfil cultural de uma determinada situação depende da configuração dinâmica dos três componentes-chave; (1), (2) ou (3) pode dominar, mas nunca eliminando outro componente. Isso significa que a posição dominante de um dos componentes pode explicar o porquê da redução dos demais.

Palavras-chave: Tradução. Cultura. Importação.

\title{
PRODUCTION, TRADITION, AND IMPORTATION: A KEY TO THE DESCRIPTION OF LITERATURE AND TRANSLATED LITERATURE
}

\begin{abstract}
In recent Translation Studies, the question of culture is a key issue. At this moment the link between translation and culture is generally accepted in the canonized theories, the difficulty is how exactly to define the cultural context. Culture indeed is both complex and multiple: which culture, what kind of a culture exactly? In empirical-descriptive research, it is crucial to establish which is the exact cultural environment and which are its relations with the neighbor cultures. Translation is one of the key areas in any cultural system and, while trying to interpret the position of translations in a given cultural system, there is no way of excluding a few hypothetical logics. Each cultural area seems to function as a synchronic and diachronic combination of (at least) three key units: (1) Production: in synchronic terms, everything a given cultural system produces (documents, activities, internal and external contacts); which takes place in a diachronic perspective; (2) Tradition: the full set of activities and positions along the diachronic axis, which of course depends on dominants options and selections (norms); (3) Importation: the organized selection of productions of neighbor cultures, - in which translation is inevitably present. The cultural profile of a given situation depends on the dynamic configuration of the three key components; (1), (2) or (3) may be dominant, but never by the full elimination of any of the other units. This implies that the dominant position of one among the components may explain why the other ones are more or less reduced.
\end{abstract}

Keywords: Translation. Culture. Importation. 
Nos últimos anos, especialistas da tradução têm se perguntado frequentemente sobre o valor das suas teorias. Alguns deles aspiram a uma teoria que, em vez de parecer um jogo de especulações tão brilhante como estéril, se destaque pela sua eficiência: trata-se de fato de interpretar sob todos os ângulos o fenômeno designado pelo termo "tradução". Disso decorre a necessidade de se levar em consideração - em vez de excluir de antemão - a diversidade histórica e cultural das traduções, sistematicamente ignorada pela maioria das teorias, presas na sincronia e nas definições normativas (Lambert, 1976).

Em vez de meditar in vitro sobre fenômenos em boa parte imaginários porque não são observados, os especialistas da tradução deveriam organizar diversos tipos de pesquisas descritivas. Obviamente, elas precisam de um embasamento teórico. O uso da teoria não tem nada de um ciclo vicioso na medida em que se pensa em um modelo hipotético e não-estático.

Sem fundamentar-se em teorias deliberadamente funcionalistas, Katharina Reiss e Werner Koller tiverem mérito em denunciar a ausência de trabalhos 'críticos' - vamos dizer 'descritivos', para evitar a orientação normativa - como uma lacuna preocupante na ciência da tradução em geral. É verdade, de fato, que as melhores publicações e os melhores colóquios consagrados à tradução, mesmo que reservem muito espaço a exemplos de pesquisas descritivas, sistematicamente negligenciam a abordagem das perspectivas teóricas e metodológicas da análise das traduções. O livro de Katharina Reiss, Möglichkeiten und Grenzen der Übersetzungskritik, representa até hoje o único do gênero, mesmo que o resultado atingido mereça muitas reservas. Destaquei em outro artigo porque a teoria geral da tradução deveria considerar as lições dadas pela tradução literária, teórica e/ou descritiva (Lambert, 1978). As considerações a seguir se referem essencialmente ao estudo descritivo da literatura em tradução, mas deveria ser possível aproveitá-las para o estudo de qualquer tradução.

A maioria das análises de traduções fica submetida às teorias estatísticas formuladas no final dos anos cinquenta: examinam-se 
sucessivamente diversos níveis do texto traduzido (nunca, ou excepcionalmente, dos textos traduzidos), começando com assuntos como o léxico, a sintaxe, o nível estilístico, ou os procedimentos de tradução (transferência, modulação, adaptação, ou implicação/ explicitação). Às vezes, os níveis textuais (por exemplo, semântico, estilístico) são combinados com os procedimentos de tradução, o que aumenta um pouco a flexibilidade da abordagem do estudo. Mas é em virtude de um pressuposto tenaz que se dá valor a priori e exclusivamente às estruturas microscópicas do texto, enquanto a natureza 'dinâmica' da equivalência - vista de várias maneiras diferentes, é verdade - é aceita de maneira bastante unânime pelos teóricos. Até em Reiss, a função da equivalência aparece na análise como um elemento entre outros, não como um fator essencial. Os aspectos macroestruturais da tradução não são ignorados oficialmente, mas na prática eles são e intervirão 'mais tarde', quando a observação microscópica tiver dado resultados. Porém, uma acumulação de elementos linguísticos nunca constituirá um texto, nem permitirá entender os princípios que motivam a sua existência.

Podemos começar, então, a partir de uma hipótese nada inesperada (mas raramente seguida), segundo a qual micro e macroestruturas se inter-relacionam e as microestruturas são funções de conjuntos mais amplos (textuais e macrotextuais).

Seguimos a contramão do método descritivo tradicional e consideramos imediatamente as traduções (literárias, publicitárias, jurídicas etc.) como um aspecto das interferências entre sistemas de comunicação (literários, publicitários, jurídicos): dentro desses sistemas, nunca totalmente autônomos e sempre complexos, um conjunto de leis e convenções é aceito como (mais ou menos) específico do sistema e de toda uma rede de subsistemas. As leis (linguísticas, morais, políticas) frequentemente acabam aparecendo como convenções, o que certamente perturba o equilíbrio do sistema. Esse equilíbrio - essa palavra descreve uma situação, sem pretensão de avaliá-la - depende essencialmente da coerência que caracteriza as normas e modelos reconhecidos como centro do sistema. O estado de equilíbrio ou desequilíbrio do sistema depende das relações entre 
o centro (o sistema dominante) e os (sub)sistemas no seu entorno. Seu funcionamento e sua evolução são orientados pelas interferências entre a produção, a tradição e a importação.

A produção designa $o$ conjunto da produção de mensagens pelos membros do sistema. Na literatura, trata-se dos textos e metatextos de todos os tipos: romances, poesia, documentos críticos, cartazes etc. É a força motriz da vida literária, situando-se a um nível diferente da tradição e da importação. Esses últimos designam a presença de elementos pertencendo a outros sistemas mas mesmo assim se relacionam, de um modo ou outro (talvez de maneira negativa, polêmica), com a literatura stricto senso, ou seja a produção.

Nenhum sistema, obviamente, é totalmente autônomo, estritamente tradicional ou inteiramente importado. Essas três categorias - que interpretamos provisoriamente como simples instrumentos descritivos, não como categorias ontológicas - nos permitem observar a estratégia seguida pelo sistema: o que importa é o valor operacional delas.

O nosso modelo é, sem dúvida, de natureza semiótica, já que nos ajuda a interpretar as interferências linguísticas, econômicas, sociais ou políticas entre duas ou varias culturas. Vamos aplicá-lo, primeiramente, à literatura e à literatura em tradução.

É tentador descrever a evolução das literaturas nacionais com a ajuda do triângulo produção-tradição-importação e a partir da teoria do polissistema. Várias relações complexas se explicam da melhor forma, de fato, como interferências entre (sub)sistemas. Contento-me em buscar algumas ilustrações a partir de uma série de certa forma ilimitada, escolhida de propósito em setores muito diversificados.

- A literatura contemporânea na Europa se tornou muito internacional, graças à importação anglo-saxã, por exemplo, também graças à literatura francesa, literatura dominante no continente, que muitas vezes serve de intermediária. Ao mesmo tempo, o peso das literaturas nacionais (e regionais) 
diminuiu. Como acontece frequentemente, tradição e importação se confrontam.

- Várias vezes, a importação acaba se confundindo com a tradição. Foi o caso dos clássicos em muitas culturas, sobretudo na França dos séculos XVII e XIX; também é o caso da literatura infanto-juvenil em diversos países (Andersen, Grimm, Perrault, à espera de Walt Disney importar uma literatura não-tradicional).

- Na verdade, produção, tradição e importação são polivalentes; seus subsetores se aliam ou lutam, dependendo das circunstâncias, mas a natureza das alianças nos permite medir a estabilidade ou o desequilíbrio do sistema. O romantismo, na literatura europeia, importa modelos e normas teóricas (aquelas que defendem os irmãos Schlegel ou Madame de Staël por exemplo) a partir de culturas estrangeiras que terão como objetivo e resultado combater o classicismo. As literaturas românticas se esforçam para substituir a tradição clássica, que se tornou tradicional, por uma tradição nacional, percebida como inovadora, que se casa sem muita dificuldade com as tradições populares estrangeiras e as produções estrangeiras modernas. Simultaneamente, uma produção 'tradicional' se mantém: ela se distingue da inovação essencialmente pelas relações que ela mantém com a tradição clássica (popular) e com a importação tradicional (inovadora).

- Em situações excepcionais, uma das três categorias leva a vantagem sobre as duas outras ou sobre uma das duas outras. Assim as letras francesas e neerlandesas da Bélgica não pararam de lutar contra a importação (francesa por boa parte, parcialmente neerlandesa também; até a importação alemã ou inglesa era parcialmente filtrada a partir da França) no decorrer do século XIX, no intuito de serem aceitas 
como uma única literatura supostamente nacional; a produção tentava escapar da destruição dando-se uma tradição. A história dos gêneros e dos subgêneros modernos na França presta-se muito bem a uma interpretação seguindo o nosso modelo. O romance histórico, o conto fantástico (e no século XX: o romance policial, as histórias em quadrinhos ou a ficção científica) implantaram-se na França como gêneros estrangeiros, até um afrancesamento progressivo se desenvolver, especialmente graças à intermediação de pseudo-traduções: procurou-se, de maneira sistemática, atribuir-lhes uma origem francesa, logo o seu sucesso era garantido.

Até aqui a tradução não foi considerada como um dos lugares em que acontecem as interferências entre produção, tradição e importação. É proposital considerarmos a 'importação' como um grupo de textos mais amplo do que aquele das traduções apenas.

Ao considerar o conjunto das obras literárias traduzidas numa determinada língua como um sistema em si, conforme as hipóteses formuladas por Even-Zohar (1978), posso considerar o estudo desse sistema e dos textos que o representam seguindo os mesmos princípios. Mostra-se muito produtivo, de fato, procurar determinar quais são as normas e modelos que regem a seleção dos textos importados, por um lado, e os traduzidos, por outro lado: são esses os dois critérios que nos autorizam a falar de um sistema de literatura traduzida. Além disso, é preciso pesquisar as inter-relações desse sistema com os sistemas que o cercam, entre os quais a literatura de origem e a literatura de chegada. Com a ajuda dessa hipótese das interferências, poderei explicar por que o Shakespeare de Ducis e de Voltaire nos lembra Racine e Corneille, ou por que Homero em francês é parecido com Ossian em francês.

Enquanto seleção de textos importados, o sistema da literatura traduzida pode se inserir - e geralmente se insere - tanto na literatura tradicional como na literatura inovadora. Ao contrário do que 
os comparatistas tendem a sublinhar, a literatura importada favorece frequentemente a tradição mais do que a inovação; durante muito tempo a literatura clássica na França bebeu na fonte dos textos latinos e gregos que eram suscetíveis de confirmar as tradições nacionais. Quando a seleção dos textos importados muda, a tradição e a produção tradicionais têm uma chance de serem redefinidas. $\mathrm{O}$ conceito da 'descoberta' das literaturas estrangeiras, utilizado por tantas histórias da literatura, aplica-se na verdade à nova seleção e não distingue a importação de textos já conhecidos.

Quase todas as teorias da tradução comprometeram a ideia de uma tradução-cópia: a tradução equivale a uma produção de textos de um tipo específico (produção de metatextos); ela é o resultado de seleções e de prioridades estabelecidas nessas seleções. Os materiais textuais - não exclusivamente linguísticos - são escolhidos, por exemplo, a partir do sistema de chegada (versão dinâmica), ou a partir do sistema de origem (versão adequada). O dilema dinâmico/adequado é um dos múltiplos canais que condicionam a produção das traduções.

A análise das traduções será acerca de:

1. Todos os níveis textuais imagináveis (léxico, sintaxe, nível, estado da língua, socioleto, idioleto, sequenciamento, estruturas narrativas, poéticas);

2. As prioridades estabelecidas entre esses níveis (o léxico pode ser sacrificado frente às normas métricas, ou as estruturas narrativas; nas versões bilíngues frequentemente é o contrário que acontece);

3. A prioridade entre adequado/dinâmico nas soluções de 1 e 2 .

Segundo as opções (dominantes), podemos representar a estratégia do tradutor e a situação do texto traduzido em um esquema: 


\begin{tabular}{l|l|l} 
LITERATURA DE & NÍVEIS & LITERATURA DE \\
ORIGEM & TEXTUAIS & \\
léxico & CHEGADA \\
& sonoridades & \\
sintaxe & ritmo & \\
& versificação & \\
parágrafos (estrofes) & \\
& personagens & \\
& nível de língua & \\
estado de língua &
\end{tabular}

Em muitos aspectos, os textos traduzidos ocupam um espaço ambíguo no conjunto das literaturas - é o que ilustra, inclusive sua posição nas discussões teóricas atuais - e entre os sistemas literários: eles representam um tipo de não-sistema ou de sistema intermediário. Como tratar exatamente o volume de textos traduzidos para o francês entre 1800 e 1850 , a partir de uma dezena de línguas? Muitos destes nunca foram concebidos como textos literários (o que não impediria que eles funcionassem assim em certos casos) e a quantidade deles que foram reconhecidos como tendo uma função literária é provavelmente limitada. A poesia japonesa, Rabindranath Tagore e qualquer poesia "exótica" em tradução escapa parcialmente das categorias descritivas em vigor nos nossos sistemas ocidentais. Para os franceses dos séculos XIX e XIX, o verdadeiro Shakespeare francês, o que podia ser apresentado a rigor, era o Shakespeare em versos de Ducis e outros, não o de Letourneur ou de François-Victor Hugo, uma tragédia em prosa não é teatro. Observando bem, encontramos aqui o nosso triângulo produção-tradição-importação de uma forma um pouco diferente, o que nos leva a posicionar com mais precisão a tradução na evolução (ou estagnação) das literaturas. Dependendo das circunstâncias, o texto traduzido desempenha uma função estrangeirizante (importação não dissimulada), uma função tradicional (submissão às convenções da literatura de chegada) ou uma função assistêmi- 
ca (a característica convencional não podendo ser atribuída nem à literatura de chegada nem à de origem). É nesse último caso que a atividade tradutória tem mais chances de encontrar a nova literatura que também se posiciona fora ou contra as convenções do momento; disso decorre a necessidade de que os grandes escritores têm de fazer experiências com textos importados a serem traduzidos; disso também decorre a tendência das literaturas a repensar a suas convenções com a ajuda da atividade tradutória.

Uma das múltiplas vantagens da nossa abordagem sistêmica é de nos fornecer ferramentas tanto para os textos adaptados, as paródias ou os comentários, ou seja, para todos os metatextos intersistêmicos, quanto para a tradução propriamente dita (que, por sinal, nunca conseguimos distinguir claramente dos outros metatextos): o estudo da tradução é, assim, integrado no estudo da literatura, sem que os seus aspectos linguísticos, socioculturais sejam ignorados.

A inserção dos textos traduzidos e adaptados nos conjuntos de comunicação, literários e outros, nos fornece quadros de referência nos quais os procedimentos e os processos básicos podem ser identificados facilmente. Como as literaturas francesa, inglesa, alemã de um determinado período concebem o discurso narrativo, os diálogos, a língua popular, a personagem trágica ou os vários gêneros poéticos? A resposta a perguntas tão variadas pode ser dada com uma rapidez e uma nitidez incríveis observando um corpus de textos traduzidos e justapondo textos representativos das várias literaturas. $\mathrm{O}$ fundamental é dispor de uma boa biblioteca e preferir observações em série a observações atomizadas. 


\section{Nota}

1. Artigo originalmente publicado em: Canadian Review of Comparative Literaturel Revue Canadienne de Littérature comparée CRCL/RCLC Spring/Printemps 1980. Este artigo, abrangendo constantemente a teoria e os estudos descritivos (históricos), origina-se de uma pesquisa comparatista de tipo descritivista sobre as relações franco-alemães; essa pesquisa foi constantemente estendida e revisada nas suas premissas teóricas; desencadeado no projeto de pesquisa: L. D'hulst, J. Lambert e K. Van Bragt, Littérature et traduction en France (1800-1850): état des travaux (Leuven: Literatuurwetenschap, 1979). Agradeço muito a Lieven D'hulst e Katrin Van Bragt por terem me ajudado a testar a tríade produção-tradição-importação. Foi Lieven D'hulst quem evidenciou a utilidade do conceito de "sistema intermediário". (Ver Sh. Yahalom, 'Le comportement d'un polyssystème littéraire en cas de crise : contacts intersystémiques et comportement traductionnel.' Comunicação apresentada no International Symposium on Translation Theory and Intercultural Relations, Tel Aviv University, March-April 1978. Atos do simpósio. Yahalom, Sh.,1979. 'Problèmes d'interférences de systèmes sémiotiques', comunicação apresentada no $2^{\circ}$ Congresso de l'AIS, Viena, 2-6.7.1979.)

\section{Referências}

Even-Zohar. Papers in Historical Poetics. Tel Aviv: Porter Institute for Poetics and Semiotics, 1978.

Katharina Reiss. Möglichkeiten und Grenzen der Übersetzungskritik. München: Hueber, 1971.

Koller, Werner. Grundprobleme der Übersetzungstheorie. Bern: Francke, 1972.

Lambert, José. "Echanges littéraires et traduction ou : études théoriques vs. études descriptives."L. Grähs. Theory and Practice of Translation. Bern: Lang, 1976.237-250. 
. "Echangeslittéraires et traduction: discussion d'un projet."Literature and Translation.New Perspectives in Leterary Studies.Holmes, J.S. et al. Louvain: Acco, 1978. 142-60.

. "Production, tradition et importation: une clef pour la description de la littérature et de la littérature en traduction." Canadian Review of Comparative Literature/ Revue Canadienne de Littérature compare, Vol. 7, No. 2, 1980. 246252.

Recebido em: 09/09/2014 Aceito em: 05/11/2014 